\title{
Prior uterine perforation resulting in intestinal obstruction in a subsequent pregnancy
}

\author{
I. Seow-En $\cdot$ F. Seow-Choen $\cdot$ P. T. L. Tseng
}

Received: 17 March 2010/Accepted: 26 July 2010/Published online: 13 August 2010

(C) Springer-Verlag 2010

A 30-year-old woman in the 30th week of her second pregnancy presented with intestinal obstruction that was confirmed by abdominal ultrasound examination.

In the patient's first pregnancy 2 years previously, a dilatation and curettage had been performed 4 weeks after delivery, to remove the retained placenta. She had developed intestinal obstruction the same night but had recovered within $48 \mathrm{~h}$, and since then had been in good health.

Due to recurrent intestinal obstruction during the patient's second pregnancy, an elective caesarean was performed at 34 weeks. A loop of bowel found herniated into a perforation in the anterior wall of the uterus was reduced, the opening in the uterine wall was closed, and she made a complete recovery (Figs. 1, 2, and 3).

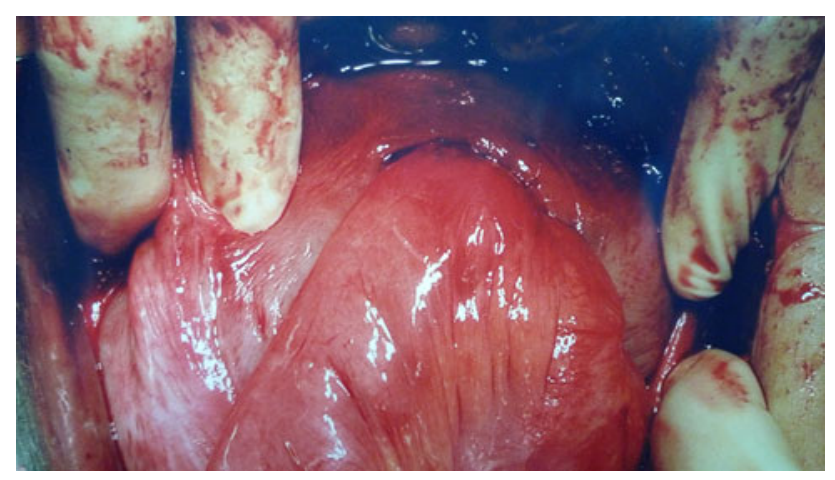

Fig. 1 The loop of small intestine herniating into the uterine perforation

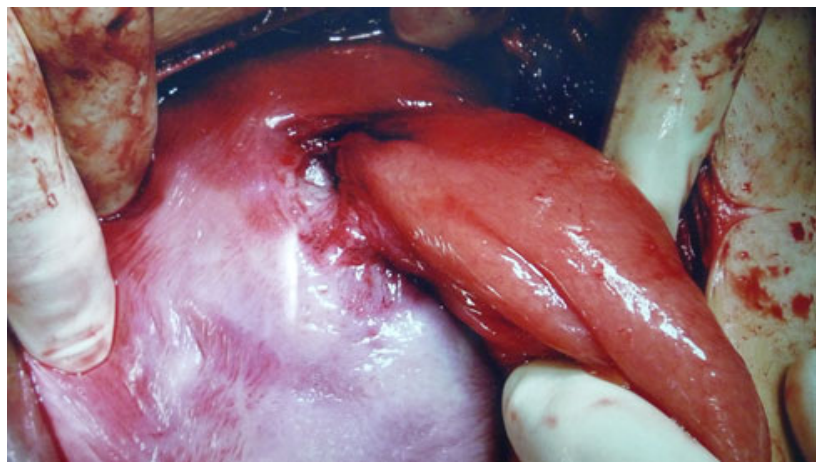

Fig. 2 The uterine perforation can be clearly seen. The dilated afferent loop is pulled aside to reveal the depth of the uterine perforation

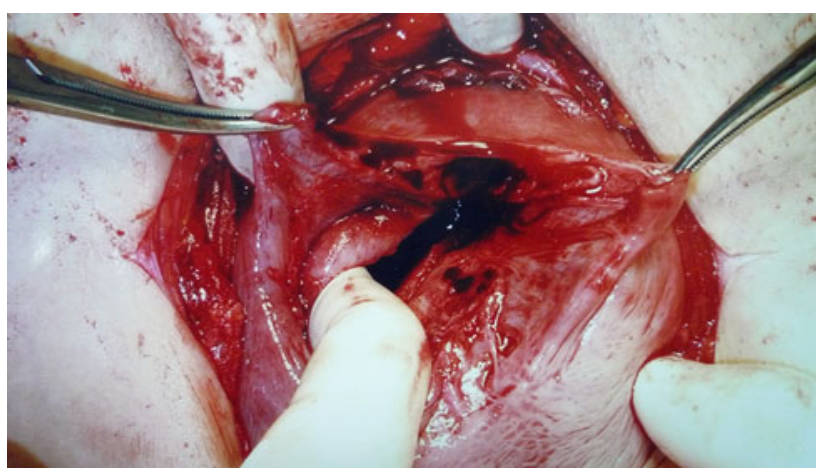

Fig. 3 The uterine perforation after the loop of bowel was cleared of adhesions and reduced
I. Seow-En · F. Seow-Choen $(\varangle) \cdot$ P. T. L. Tseng

Seow-Choen Colorectal Centre Pte Ltd., Singapore, Singapore

e-mail: seowchoen@colorectalcentre.com 